\title{
Design paper: A phase II study of Bevacizumab and Erlotinib in patients with non-Squamous non-small cell lung cancer that is refractory or relapsed after 1-2 previous Treatment (BEST)
}

Shiro Tanaka ${ }^{1 *}$, Yuichi Sakamori ${ }^{2}$, Miyuki Niimi ${ }^{1}$, Megumi Hazama ${ }^{3}$, Young H Kim² ${ }^{2}$ and Kazuhiro Yanagihara ${ }^{3,4}$

\begin{abstract}
Background: Combination of erlotinib and bevacizumab is a promising regimen in advanced non-squamous nonsmall-cell lung cancer (NSCLC). We are conducting a single arm phase II trial which aims to evaluate the efficacy and safety of this regime as a second- or third-line chemotherapy.

Methods: Key eligibility criteria were histologically or cytologically confirmed non-squamous NSCLC, stage III/IV or recurrent NSCLC not indicated radical chemoradiation, prior one or two regimen of chemotherapy, age 20 years or more, and performance status of two or less. The primary endpoint is objective response rate. The secondary endpoints include overall survival, progression-free survival, disease control rate and incidence of adverse events. This trial plans to accrue 80 patients based on a two-stage design employing a binomial distribution with an alternative hypothesis response rate of $35 \%$ and a null hypothesis threshold response rate of $20 \%$. A subset analysis according to EGFR mutation status is planned.
\end{abstract}

Discussion: We have presented the design of a single arm phase II trial to evaluate the efficacy and safety of combination of bevacizumab and erlotinib in advanced non-squamous NSCLC patients. In particular we are interested in determining the merit of further development of this regimen and whether prospective patient selection using EGFR gene is necessary in future trials.

Trial registration: This trial was registered at the UMIN Clinical Trials Registry as UMIN000004255 (http://www. umin.ac.jp/ctr/index.htm).

\section{Background}

Chemotherapy for advanced non-small-cell lung cancer (NSCLC) patients with good performance status improves survival time and quality of life [1]. Platinum doublet therapies with third-generation agents are thought as the standard in first-line for NSCLC patients, of which response rate is $30-40 \%$, one year survival rate is $26-36 \%$ and median survival time is $8-13$ months [2-4]. For patients who had relapsed or did not respond to first-line chemotherapy, docetaxel [5-7] and pemetrexed [8] are effective. Erlotinib, an oral epidermal growth

\footnotetext{
* Correspondence: shiro@kuhp.kyoto-u.ac.jp

'Department of Clinical Trial Design and Management, Translational Research Center, Kyoto University Hospital, 54 Shogoin Kawahara-cho, Sakyoku, Kyoto 606-8507, Japan

Full list of author information is available at the end of the article
}

factor receptor tyrosine kinase inhibitor (EGFR-TKI), was also shown to improve progression-free survival (PFS) and overall survival (OS) modestly with acceptable toxicity in second- or third-line setting for advanced NSCLC $[9,10]$. On third-line treatment only erlotinib is recommended by the National Comprehensive Cancer Network guideline [11] and no established treatment options exist for patients who have experienced erlotinib failure.

Several lines of evidence lent support to the notion that combining bevacizumab, a monoclonal antibody targeting the vascular endothelial growth factor (VEGF), with erlotinib for advanced NSCLC might confer additional clinical benefit. Two large phase III trials confirmed that bevacizumab improves survival of advanced non-squamous NSCLC patients when combined with carboplatin plus 
paclitaxel or cisplatin plus gemcitabine as first-line chemotherapy [12,13]. A significant improvement in PFS and objective response rate (ORR) by the addition of bevacizumab with carboplatin plus paclitaxel was also shown in a randomize phase II trial of Japanese patients [14]. Finally, a recent randomized phase II trial of combination of bevacizumab with erlotinib, combination with cytotoxic drug, and cytotoxic drugalone showed results for PFS and OS favour the combination regimens over cytotoxic drug alone in the second-line setting, although not statistically significant [15].

\section{Objective}

The primary objective of the trial is to evaluate the efficacy and safety of combination of bevacizumab and erlotinib as a second- or third-line chemotherapy for advanced nonsquamous NSCLC. Specific hypotheses to be tested are (1) one-sided hypothesis that the ORR of combination of bevacizumab and erlotinib is higher than a pre-specified threshold of $20 \%$, (2) whether this regimen are safe and feasible, and (3) whether the ORR is higher in patients with EGFR mutation than in patients with EGFR wild type.

\section{Methods}

\section{Design and setting}

This study is an open-label, multi-institute, single arm phase II clinical trial. The coordinating office is at Kyoto University Hospital. Registration and data collection are conducted with the use of the web system and the electronic case report form (e-CRF).

\section{Ethical consideration and registration}

The study protocol is according to the Helsinki declaration [16] and the Ethics Guidelines for Clinical Research by the Ministry of Health, Labor, and Welfare [17]. We obtained approval by the ethical committee at Kyoto University on October 27, 2010 (C-453). This trial was registered at the UMIN Clinical Trials Registry as UMIN000004255 (http://www.umin.ac.jp/ctr/index.htm).

\section{Eligibility criteria}

Staging was according to the 7th Edition of the TNM Classification for Lung Cancer [18]. Inclusion criteria are as follows:

1) Histologically or cytologically confirmed non-squamous NSCLC.

2) Stage III/IV or recurrent NSCLC not indicated radical chemoradiation, and prior one or two regimen of chemotherapy.

3) Age 20 years or more at the date of informed consent.

4) The Eastern Cooperative Oncology Group Performance Status of two or less.

5) Presence of measurable lesion.
6) Sufficient hematologic, hepatic, and renal and lung function in laboratory tests 14 days before registration.

7) Expected survival time more than three months.

8) Expected interval more than 28 days after surgery if the patient received a major surgery.

9) Written informed consent by the patient.

Exclusion criteria are as follows:

1) Prior EGFR-TKI.

2) Serious complications.

3) Hemoptysis or bloody sputum of $2.5 \mathrm{~mL}$ or more, or history of clinically significant hematemesis, coagulation disorder or thrombosis.

4) A cavitating lesion, a central lesion or a lesion abutting major blood vessels.

5) History of myocardial or cerebral infarction within six months before registration.

6) Refusal of contraception or woman with on-going or contemplating pregnancy or breast-feeding.

7) Brain metastasis with a bleeding risk.

8) Interstitial pneumonia confirmed by computer tomography.

9) Difficulty in ingestion.

10) Pleural effusion which is uncontrolled by local therapy and requires other treatments

11) Patients judged inappropriate for the trial by investigators.

\section{Patient registration}

After confirming eligibility criteria and obtaining informed consent. Eligible patients are registered and then investigators initiate the planned treatment. The accrual started in November 2010 and is to continue for two years.

\section{Treatment}

Patients enrolled in this trial receive the protocol treatment with bevacizumab and erlotinib within 15 days. Dose of the protocol treatment is based on the prior trials $[15,19]$. Bevacizumab is administered at a dose of $15 \mathrm{mg} / \mathrm{kg}$ on the first day of each 3-week cycle. No dose reductions are allowed for bevacizumab. Bevacizumab is terminated if either of the following adverse events occurs.

1) Grade 2 to 4 hemorrhage

2) Grade 3 to 4 thrombosis

3) Delay of administration of each cycle over 23 days

Erlotinib is administered initially at $150 \mathrm{mg} /$ day orally. Tablets are taken at least one hour before or two hours after a meal, preferably in the morning. Dose of erlotinib are reduced by one or two levels of five doses, 150, 125, 100,75 and $50 \mathrm{mg}$, if either of the following adverse events occurs.

1) Unacceptable skin toxicity

2) An increase in AST or ALT up to Grade 3 to 4 
3) Grade 3-4 diarrhea

Dose escalations for erlotinib are not allowed after a dose reduction. Erlotinib is terminated if either of the following adverse events occurs.

1) Grade 1 to 4 pulmonary fibrosis

2) Grade 4 non-hematologic toxicity other than pulmonary fibrosis

3) Delay from prior administration over 23 days

The protocol treatment is terminated if the disease progresses, serious adverse events occurs or at the patient's refusal. There is no restriction of maximum number of cycles. There is no restriction of treatment after failure of the protocol treatment.

\section{Endpoints}

The primary endpoint is ORR. The secondary endpoints are PFS, OS, disease control rate (DCR) and incidence of adverse events. Patients undergo tumor assessments at baseline and every six weeks by investigators using Response Evaluation Criteria in Solid Tumors version 1.1 [20]. ORR and DCR are defined by the proportion of complete response (CR) and partial response (PR), or the proportion of CR, PR and stable disease (SD), in confirmed best overall response at the time of the primary analysis. OS is defined as the time from registration to death from any cause, and it is censored at the last contact date for living patient. PFS is defined as the time from registration to either the first event of progression of disease or death from any cause, and it is censored at the last date when patient is alive without progression. Adverse events are evaluated according to the Common Terminology Criteria for Adverse Events (CTCAE) version 4.0 [21].

\section{Data collection}

Patients are followed-up for three months after registration. Schedule of data collection are summarised in Table 1. Radiographic data for tumor assessments is collected every six weeks.

\section{Sample size determination}

Simon's minimax two-stage design employing a binomial distribution is used to calculate the required sample size. In the previous trials, the ORR of erlotinib monotherapy ranged 8.9 to $28.3 \%[9,10]$. Thus we consider that an ORR of $20 \%$ indicates no value of further investigation of the combination. This trial plans to accrue 42 patients in the first stage and 80 patients in total, which provides $90 \%$ power with an alternative hypothesis ORR of $35 \%$ and a null hypothesis ORR of $20 \%$ using one-sided testing at a $5 \%$ significance level.

\section{Statistical consideration}

The analysis population for efficacy is the full analysis set. The primary analysis for efficacy is a one-sided binomial test with the null hypothesis of $20 \%$ at a $5 \%$ significance level in the second stage. A subset analysis according to EGFR mutation status (direct sequence or PNA-LNA PCR clamp methods) is also planned. ORRs with $95 \%$ confidence intervals are calculated in the subsets of mutant and wild type, and compared with $20 \%$ using the same

Table 1 Schedule of data collection

\begin{tabular}{|c|c|c|c|c|}
\hline & Baseline & $\begin{array}{c}\text { Under } \\
\text { treatment }\end{array}$ & $\begin{array}{c}\text { At termination } \\
\text { of treatment }\end{array}$ & $\begin{array}{c}\text { After termination } \\
\text { of treatment }\end{array}$ \\
\hline \multicolumn{5}{|l|}{ Physical examination } \\
\hline Height & $\circ$ & & & \\
\hline Weight, performance status & $\circ$ & $\circ$ & $\circ$ & \\
\hline Blood pressure & $\circ$ & $\circ$ & $\circ$ & $\circ$ \\
\hline \multicolumn{5}{|l|}{ Laboratory test } \\
\hline Blood count & $\circ$ & $\circ$ & & \\
\hline Biochemistry test & $\circ$ & $\circ$ & & \\
\hline Urine test & $\circ$ & $\circ$ & & \\
\hline $\mathrm{SpO}_{2}$ & $\circ$ & $\circ$ & & $0^{* 1}$ \\
\hline Electrocardiography & $\circ$ & $0^{* 1}$ & & \\
\hline EGFR gene & $\circ$ & & & \\
\hline \multicolumn{5}{|l|}{ Radiology test } \\
\hline Chest Xp & $\circ$ & $0^{* 1}$ & & $0^{* 1}$ \\
\hline Chest $C T$ & $\circ$ & $0^{* 2}$ & & $0^{* 3}$ \\
\hline Abdominal CT/Ultra sonography & $\circ$ & $0^{* 2}$ & & $0^{* 3}$ \\
\hline Head CT/MRI & $\circ$ & $0^{* 1}$ & & $0^{* 1}$ \\
\hline Bone scintigraphy/PET & $\circ$ & $0^{* 1}$ & & $0^{* 1}$ \\
\hline
\end{tabular}

*1 If necessary

*2 Every 6 weeks

*3 Six weeks after termination if treatment is terminated for reasons other than progression of disease 
binomial test at a 5\% significance level separately. Multiplicity is not adjusted for since this is a secondary analysis.

\section{Discussion}

We have presented the design of a single arm phase II trial to evaluate the efficacy and safety of combination of bevacizumab and erlotinib in advanced non-squamous NSCLC patients. In particular we are interested in determining the merit of further development of this regimen and whether prospective patient selection using EGFR gene is necessary in future trials.

\section{List of abbreviations used}

CR: complete response; CTCAE: the Common Terminology Criteria for Adverse Events; NSCLC: non-small-cell lung cancer; e-CRF: electronic case report form; EGFR-TKI: epidermal growth factor receptor tyrosine kinase inhibitor; ORR: objective response rate; OS: overall survival; PR: partial response; PFS: progression-free survival; SD: stable disease; VEGF: vascular endothelial growth factor.

\section{Acknowledgements and Funding}

The authors would like to thank the staff in participating institutes for their support in recruiting eligible patients and the patients who participated in this study.

\section{Author details}

'Department of Clinical Trial Design and Management, Translational Research Center, Kyoto University Hospital, 54 Shogoin Kawahara-cho, Sakyoku, Kyoto 606-8507, Japan. ${ }^{2}$ Department of Respiratory Medicine, Graduate School of Medicine, 54 Shogoin Kawahara-cho, Sakyo-ku, Kyoto 606-8507, Kyoto University, 606-8507, Japan. ${ }^{3}$ Outpatient Oncology Unit, Kyoto University Hospital, 54 Shogoin Kawahara-cho, Sakyo-ku, Kyoto 606-8507, Japan. ${ }^{4}$ Department of Translational Clinical Oncology, Graduate School of Medicine, 54 Shogoin Kawahara-cho, Sakyo-ku, Kyoto 606-8507, Kyoto University, 606-8507, Japan.

\section{Authors' contributions}

$\mathrm{KY}$ conceived of the trial. $\mathrm{KY}, \mathrm{MH}, \mathrm{YS}, \mathrm{ST}$ and $\mathrm{MN}$ designed the trial. $\mathrm{MH}$ searched the literature and drafted the protocol. MN supervised the data management and patient registration. ST is responsible for statistical analysis. ST wrote the final manuscript. All authors have read and approved the final manuscript.

\section{Competing interests}

KY received research funding from Taiho Pharmaceutical and Chugai Pharmaceutical. The other authors declare no competing interests.

Received: 14 February 2011 Accepted: 12 May 2011

Published: 12 May 2011

\section{References}

1. Wozniak AJ, Crowley JJ, Balcerzak SP, Weiss GR, Spiridonidis CH, Baker LH, Albain KS, Kelly K, Taylor SA, Gandara DR, Livingston RB: Randomized trial comparing cisplatin with cisplatin plus vinorelbine in the treatment of advanced non-small-cell lung cancer: a Southwest Oncology Group study. J Clin Oncol 1998, 16:2459-2465.

2. Schiller JH, Harrington D, Belani CP, Langer C, Sandler A, Krook J, Zhu J, Johnson DH, Eastern Cooperative Oncology Group: Comparison of four chemotherapy regimens for advanced non-small-cell lung cancer. N Engl J Med 2002, 346:92-98.

3. Edelman MJ, Clark Jl, Chansky K, Albain K, Bhoopalam N, Weiss GR, Giguere JK, Kelly K, Crowley J, Gandara DR: Randomized phase II trial of sequential chemotherapy in advanced non-small cell lung cancer (SWOG 9806): carboplatin/gemcitabine followed by paclitaxel or cisplatin/vinorelbine followed by docetaxel. Clin Cancer Res 2004, 10:5022-5026.
4. Yasuda H, Yamaya M, Nakayama K, Sasaki T, Ebihara S, Kanda A, Asada M, Inoue D, Suzuki T, Okazaki T, Takahashi H, Yoshida M, Kaneta T, Ishizawa K, Yamanda S, Tomita N, Yamasaki M, Kikuchi A, Kubo H, Sasaki H: Randomized phase II trial comparing nitroglycerin plus vinorelbine and cisplatin with vinorelbine and cisplatin alone in previously untreated stage IIIB/IV non-small-cell lung cancer. J Clin Oncol 2006, 24:688-694.

5. Shepherd FA, Dancey J, Ramlau R, Mattson K, Gralla R, O'Rourke M, Levitan N, Gressot L, Vincent M, Burkes R, Coughlin S, Kim Y, Berille J: Prospective randomized trial of docetaxel versus best supportive care in patients with non-small-cell lung cancer previously treated with platinum-based chemotherapy. J Clin Oncol 2000, 18:2095-2103.

6. Fossella FV, DeVore R, Kerr RN, Crawford J, Natale RR, Dunphy F, Kalman L, Miller V, Lee JS, Moore M, Gandara D, Karp D, Vokes E, Kris M, Kim Y, Gamza F, Hammershaimb L: Randomized phase III trial of docetaxel versus vinorelbine or ifosfamide in patients with advanced non-smallcell lung cancer previously treated with platinum-containing chemotherapy regimens. The TAX 320 Non-Small Cell Lung Cancer Study Group. J Clin Oncol 2000, 18:2354-2362.

7. Pfister DG, Johnson DH, Azzoli CG, Sause W, Smith TJ, Baker S Jr, Olak J, Stover D, Strawn JR, Turrisi AT, Somerfield MR, American Society of Clinical Oncology: American Society of Clinical Oncology treatment of unresectable non-small-cell lung cancer guideline: update 2003. J Clin Oncol 2004, 22:330-353.

8. Hanna N, Shepherd FA, Fossella FV, Pereira JR, De Marinis F, von Pawel J, Gatzemeier U, Tsao TC, Pless M, Muller T, Lim HL, Desch C, Szondy K, Gervais R, Shaharyar, Manegold C, Paul S, Paoletti P, Einhorn L, Bunn PA Jr: Randomized phase III trial of pemetrexed versus docetaxel in patients with non-small-cell lung cancer previously treated with chemotherapy. J Clin Oncol 2004, 22:1589-1597.

9. Shepherd FA, Rodrigues Pereira J, Ciuleanu T, Tan EH, Hirsh V Thongprasert S, Campos D, Maoleekoonpiroj S, Smylie M, Martins R, van Kooten M, Dediu M, Findlay B, Tu D, Johnston D, Bezjak A, Clark G, Santabárbara P, Seymour L, National Cancer Institute of Canada Clinical Trials Group: Erlotinib in previously treated non-small-cell lung cancer. N Engl J Med 2005, 353(2):123-132.

10. Kubota K, Nishiwaki Y, Tamura T, Nakagawa K, Matsui K, Watanabe K, Hida T, Kawahara M, Katakami N, Takeda K, Yokoyama A, Noda K, Fukuoka M, Saijo N: Efficacy and safety of erlotinib monotherapy for Japanese patients with advanced non-small cell lung cancer: a phase II study. J Thorac Oncol 2008, 3(12):1439-1445.

11. National Comprehensive Cancer Network: Non-small cell lung cancer. NCCN Clinical Practice Guidelines in Oncology, v.2 2010.

12. Sandler A, Gray R, Perry MC, Brahmer J, Schiller JH, Dowlati A, Lilenbaum R, Johnson DH: Paclitaxel-carboplatin alone or with bevacizumab for nonsmall-cell lung cancer. N Engl J Med 2006, 355(24):2542-2550.

13. Reck M, von Pawel J, Zatloukal P, Ramlau R, Gorbounova V, Hirsh V, Leighl N, Mezger J, Archer V, Moore N, Manegold C: Phase III trial of cisplatin plus gemcitabine with either placebo or bevacizumab as firstline therapy for nonsquamous non-small-cell lung cancer: AVAil. J Clin Oncol 2009, 27(8):1227-1234.

14. Nishio M, Horai T, Kunitoh $H$, Ichinose $Y$, Nishiwaki $Y$, Hida T, Yamamoto $N$ Kawahara M, Saijo N, Fukuoka M, JO19907 Study Group: Randomized, open-label, multicenter phase II study of bevacizumab in combination with carboplatin and paclitaxel in chemotherapy-naive Japanese patients with advanced or recurrent nonsquamous non-small cell lung cancer (NSCLC): JO19907. J Clin Oncol 2009, 27(15S):8036.

15. Herbst RS, O'Neill VJ, Fehrenbacher L, Belani CP, Bonomi PD, Hart L, Melnyk O, Ramies D, Lin M, Sandler A: Phase II study of efficacy and safety of bevacizumab in combination with chemotherapy or erlotinib compared with chemotherapy alone for treatment of recurrent or refractory non small-cell lung cancer. J Clin Oncol 2007, 25(30):4743-4750.

16. The World Medical Association: WMA Declaration of Helsinki - Ethical Principles for Medical Research Involving Human Subjects [http://www.wma. net/en/30publications/10policies/b3/17c.pdf], accessed on December 16, 2010.

17. The Ministry of Health, Labor, and Welfare: Ethics Guidelines for Clinical Research [http://www.mhlw.go.jp/general/seido/kousei/i-kenkyu/index.html], accessed on December 16, 2010

18. UICC International Union Against Cancer: TNM classification of malignant tumours. 7 edition. Wiley-Blackwell, New York; 2009. 
19. Herbst RS, Johnson DH, Mininberg E, Carbone DP, Henderson T, Kim ES, Blumenschein G Jr, Lee JJ, Liu DD, Truong MT, Hong WK, Tran H, Tsao A, Xie D, Ramies DA, Mass R, Seshagiri S, Eberhard DA, Kelley SK, Sandler A: Phase I/II trial evaluating the anti-vascular endothelial growth factor monoclonal antibody bevacizumab in combination with the HER-1/ epidermal growth factor receptor tyrosine kinase inhibitor erlotinib for patients with recurrent non-small-cell lung cancer. J Clin Oncol 2005, 23(11):2544-2555.

20. Therasse P, Arbuck SG, Eisenhauer EA, Wanders J, Kaplan RS, Rubinstein L, Verweij J, Van Glabbeke M, van Oosterom AT, Christian MC, Gwyther SG: New guidelines to evaluate the response to treatment in solid tumors. European Organization for Research and Treatment of Cancer, National Cancer Institute of the United States, National Cancer Institute of Canada. J Natl Cancer Inst 2000, 92(3):205-216.

21. The Japanese Clinical Oncology Group: Japanese version of the Common Terminology Criteria for Adverse Events version 4.0 [http://www.jcog.jp/ doctor/tool/CTCAEv4J_20100201.pdf], accessed on December 16, 2010.

doi:10.1186/1745-6215-12-120

Cite this article as: Tanaka et al:: Design paper: A phase II study of Bevacizumab and Erlotinib in patients with non-Squamous non-small cell lung cancer that is refractory or relapsed after 1-2 previous Treatment (BEST). Trials 2011 12:120.

\section{Submit your next manuscript to BioMed Central} and take full advantage of:

- Convenient online submission

- Thorough peer review

- No space constraints or color figure charges

- Immediate publication on acceptance

- Inclusion in PubMed, CAS, Scopus and Google Scholar

- Research which is freely available for redistribution

Submit your manuscript at www.biomedcentral.com/submit 